\title{
Doing Structural Coordination Chemistry Research with Limited Funds
}

\author{
Mark A. Whitener \\ Department of Chemistry and Biochemistry, Montclair State University, Upper Montclair, NJ, \\ 07043, USA, whitenerm@mail.montclair.edu
}

In the 26 years since I started at Montclair State University, the startup packages for tenure track faculty have increased by approximately an order of magnitude from $\$ 30,000$ to $\$ 300,000$. In 1993 , I was given no startup funds, but a promise of priority in a now defunct capital equipment program from the state of New Jersey that allowed me to obtain a diffractometer. I also had the use of any chemicals and apparatus in the stockroom and equipment inherited from the lab of my predecessor. I also could request small amounts of chemicals from a budget set aside for student research.

I realized early in my career that I was not good at writing grants. I was able to purchase some small laboratory equipment and chemicals from a PRF for $\$ 25,000$ awarded early in my career. I established a research program in structural coordination chemistry using cheap (imidazole) and available chemicals (metal salts and carboxylic acids from the stockroom). I will describe some of the interesting structures discovered through these studies. I am aided in these endeavors through collaborations with other crystallographers. 